\title{
Avaliação Ecotoxicológica em Corpos D 'Água: Um Estudo de Caso do Açude do Polo Petroquímico de Camaçari, Bahia
}

\author{
Graça Regina Armond M atias Ferreira, Laf ayette Dantas da Luz, Iracema Andrade N ascimento \\ Departamento de Engen haria A mbiental - Instituto de Biologia/U FBA \\ ginamatias@hotmail.com; Iluz@ufba.br \\ Mauro de Freitas Rebelo \\ Instituto de Biofísica/UFR J
}

Recebido: 13/06/08 -revisado: 14/10/09 -aceito: 19/08/10

\begin{abstract}
RESUM 0
A presen ça de compostos aromáticos no ambiente deve ser objeto de monitoramento, devido ao alto poder carcinogê nico e à capacidade de modificar a expressão de genes, desen cadeando a formaçãao das proténas, cuja in dução pode ser de terminada por técnica específica para hidrocarbon etos poliaromáticos (H PA's), Bifenis Policlorados (PCB's) e Dioxinas Organocloradas. Este artigo avalia a biodisponibilidade de compostos aromáticos em um reservatório (açude) receptor de águas pluviais de áreas industriais do Pólo Petroquímico de Camaçari (Bahia). Os testes têm base nas respostas biológicas em tilápias, Oreochromis niloticus, expostas a amostras de água e sedimento. A análise baseou-sena in du ção enzimática en volvendo a oxidação de xen obióticos que vem ten do grande su cesso como biomarcadores de exposição a H PAs e outros poluentes oriundos de atividades industriais. A utilização desta técnica é associada ao au men to de atividade enzimática nos hepatócitos dos organismos, indicando o primeiro sinal para avaliar a indução e presen ça/ ausência dos compostos aromáticos no ambiente. Os resultados dos testes in dicaram que os pexes submetidos às amostras da área de estudo foram expostos a compostos aromáticos, por apresentarem um aumento enzimático significativo nos hepatócitos. Entretanto, esta contaminação pode ser definida como significativamente moderada, provavelmente devido a menor biodisponibilidade dos contaminantes presentes. 0 estu do desenvolvido permitiu o conhecimento e teste de uma nova tecn ologia, auxilian do a preservação ambiental e dos recursos hídricos da região.
\end{abstract}

Palavras-chave: contamin ação; polui ção; compostos aromáticos; biomarcador; preven ção; impacto ambiental.

\section{INTRODUÇÃO}

Os ecossistemas aquáticos, de uma forma geral, se constituem em grandes receptáculos de efluentes, variáveis quanto a sua constituição e em quantidade e origem. A toxicidade de efluentes líquidos pode ser ocasionada por substâncias orgânicas ou inorgânicas, utilizadas nos processos produtivos e auxiliares, nos diversos segmentos das atividades antrópicas. Para a avaliação dos efeitos destes contaminantes sobre a biota, alguns aspectos devem ser considerados, tais como biodisponibilidade e interação das várias substâncias (sinergismos e antagonismos), que podem determinar a ocorrência e alterar a intensidade de um efeito tóxico, seja de efluentes tratados ou não. Outro aspecto a ser considerado é a vazão de lançamento do efluente, em relação à do corpo receptor, pois é a partir desta relação (Carga Tóxica $=$ Vazão $\times$ Toxicidade do efluente) que se estabelecerão os níveis de toxicidade aceitáveis para lançamento do efluente (CETESB, 1990a; 1990b) em corpos receptores.

Condições ambientais deletérias podem ser aumentadas pelo crescimento industrial. Particularmente, os ecossistemas aquáticos têm sido os maiores prejudicados pelos impactos causados pelo número crescente de descargas de compostos químicos estranhos a um organismo ou sistema biológico (i.e. xenobióticos). A exposição de organismos à esses compostos, promove uma interação entre sistemas químicos e biológicos, que pode causar distúrbios e/ ou respostas adaptativas (Bainy et al., 1996; Mendiondo et al., , 2002). Entretanto, as concentrações necessárias para causar efeitos letais e subletais nos organismos variam de acordo com o ambiente receptor, devido a grande variabilidade química no ecossistema aquático (Crapez, 2001).

Poluição e degradação de qualidade de água restringem a utilização deste recurso (Paiva e Paiva, 
2002). A caracterização dos recursos hídricos deve se dar com relação a sua quantidade e a sua qualidade, estando essas características intimamente relacionadas (Azevedo et al., 2003). A busca de ferramentas que visem análises quali-quantitativas de contaminantes em ecossistemas aquáticos, tornou-se um desafio contínuo para cientistas ambientais (CETESB, 1990a). A Resolução 357/ 2005 do CONAMA passou a ser referência, em termos legislativos, adotando a exigência do estudo de toxicidade dos efluentes antes destes serem lançados ao corpo hídrico.

Tendo em vista a complexidade causada pela interação dos agentes químicos, os efeitos biológicos dos efluentes não podem ser caracterizados simplesmente por análises químicas tradicionais. Análises físico-químicas permitem a identificação e quantificação de poluentes, mas não determinam sua toxicidade. 0 uso integrado de análises físicas, químicas e ecotoxicológicas é uma estratégia mais eficiente para avaliar o risco ambiental (Bertoletti 1990; Costan \& al., 1993) e, consequentemente, prevenir danos.

Através de bioensaios, utilizan do exemplares da biota local, se pode atuar de forma proativa, além de reativa, em relação a possíveis impactos causados por xenobióticos no ecossistema receptor (Santana et al., 2002). O uso de biomarcadores e de outros ensaios ecotoxicológicos apresentam um grande potencial no sentido de predizer danos ecológicos e riscos à saúde, sendo utilizados como ferramentas de avaliação de impacto ambiental e de biomonitoramento por serem considerados instrumentos preventivos em programas de controle de qualidade da água.

Este artigo avalia a biodisponibilidade de compostos aromáticos em um reservatório (açude) receptor de águas de áreas industriais do Pólo Petroquímico de Camaçari (Bahia). A investigação visou detectar a biodisponibilidade de compostos aromáticos, utilizando novas metodologias para elucidar como os estressores são capazes de modificar a expressão de genes, desencadeando a formação das proteínas, cuja indução foi determinada pela técnica específica para HPAs, PCB's e Dioxinas Organocloradas. Esse estudo possibilitou o conhecimento e teste de uma nova tecnologia voltada à preservação ambiental e dos recursos hídricos da região.

\section{O USO DE BIOMARCADORES}

Os biomarcadores são definidos como alterações biológicas de aviso, que expressam a exposi- ção e podem expressar os efeitos tóxicos dos poluentes presentes no ambiente ( $\mathrm{Lam} \& \mathrm{Wu}, 1999$; Bainy, 2001). Características como predição (early warning - antecipação), sensibilidade, especificidade e baixo custo, fazem dos biomarcadores uma ferramenta útil em programas de monitoramento ambiental.

0 uso do citocromo P-450 como biomarcador de exposição e efeito, apresenta vantagens sobre outros biomarcadores por ser específico para indicar preventivamente locais poluídos por hidrocarbonetos aromáticos e PCBs. Como a indução deste sistema enzimático envolve reações defensivas iniciais do organismo em resposta a estes estressores, possibilita ações preventivas contra efeitos mais profundos que poderiam se manifestar, em última instância, como alterações em populações, comunidades ou mesmo em todo o ecossistema. A mesma técnica pode ser usada para obtenção de respostas orgânicas, como indicadoras em estudos de recuperação de áreas já degradadas.

Os citocromos P450 (CY P) constituem uma grande família de hemoproteínas, encontradas nas membranas do retículo endoplasmático dos hepatócitos e de outras células corporais (Ehlers-Marcussen \& Barra, 1997; Bistolas et al., 2005), responsáveis pela biotransformação de compostos orgânicos, promovendo a catálise da monooxigenação de uma diversidade de substratos hidrofóbicos (Nebert, 2000; Bainy et al., 2001; Axarli et al., 2005; Siroka et al., 2005).

Em peixes o CY P1A é o principal componente da fase I de biotransformação de xenobióticos, induzido por contaminantes orgânicos, tais como hidrocarbonetos policíclicos aromáticos (HPAs). A atividade de etoxiresorufina-O-desetilase (EROD) é catalisada principalmente por CY P1A em fígado de diversas espécies, sobretudo em peixes. A expressão da atividade EROD é a metodologia mais empregada para determinação da atividade catalítica do CY P1A, embora seja uma medida indireta da expressão da proteína, que vem sendo comumente utilizada como primeiro sinal para se avaliar sua indução, devido à sua elevada sensibilidade e especificidade à exposição (Huevel al., 1995; Sleiderink et al., 1995; Adams et al, 1996; Burgeot et al., 1996; Pedroza et al., 2002; Rees et al, 2005) .

\section{MATERIAL E MÉTODOS}

Área de estudo

A área de estudo compreende um corpo receptor de efluentes e drenagem pluvial de áreas 
industriais, localizada no Pólo Petroquímico de Camaçari. Este complexo industrial situa-se entre os municípios de Camaçari e Dias D' Ávila, na região metropolitana de Salvador, a cerca de $56 \mathrm{~km}$ desta capital, sendo integrado por diversas indústrias do ramo petroleiro que iniciaram sua operação na década de 70 e que vêm aumentando a sua produção.

Efluentes não orgânicos são lançados sem nenhum tratamento e contaminantes tóxicos podem estar presentes no açude. Apesar da presença de placas informativas de proibição de uso para fins de pesca, o açude é utilizado para este fim por pessoas de baixa renda, podendo acarretar sérios danos a saúde da população pela ingestão de organismos contaminados. 0 primeiro aspecto a ser considerado quando são avaliados os efeitos induzidos por contaminantes químicos presentes na biota (respostas biológicas) é que, em ambientes naturais, o organismo pode estar exposto a uma miríade ou mistura de diferentes contaminantes ao mesmo tempo (efeitos sinérgicos) (Rand et al., 1994).

\section{Amostragem}

Os organismos utilizados nos ensaios (Tilápia do Nilo -Oreochromis niloticus) foram fornecidos pelo Departamento Nacional de Obras contra as Secas (DNOCS), onde foram criados sob condições controladas, livres de contaminação. As coletas de água e sedimento do local de estudo foram realizadas em 6 campanhas, 3 delas no período de seca e 3 em período chuvoso.

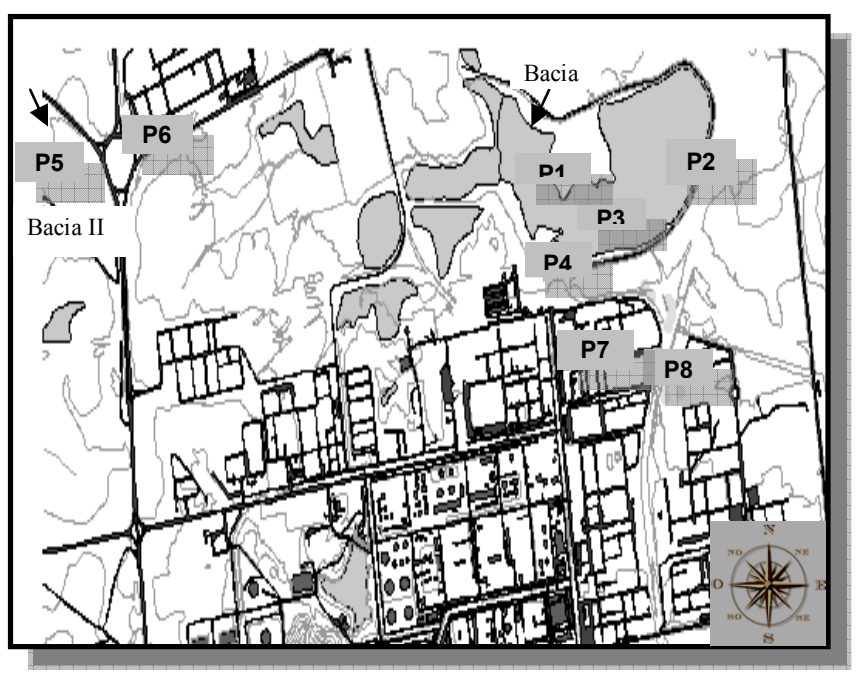

Figura 1 -L ocalização do açude de retenção de efluentes e pontos de amostragem
Os pontos de amostragem foram definidos em função da localização e importância dos mesmos para análise, com base nas contribuições dos efluentes das empresas. Foram definidos oito pontos amostrais indicados como P1 a P8, sendo: P1 - Borda oeste do açude; P2 - Borda leste do Açude; P3 Parte mais profunda do Açude; P4 - Interior do Açude (próximo à chegada das ruas Hidrogênio) e P5 - Interior da Bacia do Cobre. Os pontos P6 Canal da Bacia do Cobre; P7 - Canal de Reversão do Açude I e P8 -Canal Final. Nos pontos P1 a P5 foram coletadas amostras líquidas (Garrafa Van Dorn) e sedimento (Draga de Pettersen). Nos pontos P6 a P8 foram coletadas somente amostras líquidas, por se tratar de um canal. As amostras coletadas foram levadas ao LABIOMAR, onde o trabalho experimental foi realizado obedecendo a protocolos do laboratório (CETESB, 1990a; CETESB,1990b; Nascimento, 2000; Nascimento, 2002).

\section{Exposição dos organismos}

As amostras foram testadas em aquários com capacidade de 10L, distribuídas em 5 réplicas por ponto. Para os testes com água superficial foram utilizados 4L de amostra/ aquário e para os testes com sedimento usados $300 \mathrm{~g}$ da amostra/ aquário nos quais foi adicionada água de diluição, perfazendo um volume total de $4 \mathrm{~L}$ no aquário. Em cada aquário foi colocado um (01) peixe (juvenil de tilápia), o qual foi exposto por vinte e quatro (24) horas sob condições ambientais adequadas, incluindo aeração.

Antes e no final dos testes foram determinados parâmetros físico-químicos como temperatu$\mathrm{ra}, \mathrm{pH}$, salinidade e oxigênio dissolvido, através de aparelho multiparâmetro; nitrato, amônia e dureza da água, pela técnica descrita no Standard Methods (1995); além da determinação de carbono orgânico por calcinação e da granulometria. Os valores medidos foram comparados com os limites estabelecidos pela Resolução CONAMA no 357/ 05 para classificação de uso da água.

De acordo com a resolução CONAMA no $344 / 2004$, que rege as diretrizes de dragagem de sedimentos, foi feita a comparação pelo nível 1 "Iimiar abaixo do qual se prevê baixa probabilidade de efeitos adversos à biota" para identificar pontos que apresentem algum risco.

\section{Determinação da fração citosólica}

Após a exposição, todos os peixes foram sacrificados, mensurados e pesados. 0 fígado de cada animal foi extraído, pesado, divido em 4 partes. Para 
a realização dos testes, $1 / 2$ do fígado foi lavado com $\mathrm{KCl}$ 0,15 M para remoção dos resíduos de sangue; e em seguida mergulhado em nitrogênio líquido ( para rápido congelamento) e armazenado em freezer 80 ㅇ $\mathrm{C}$ para uso posterior. Fígados de 5 peixes, provenientes de cada ponto amostral (P1 a P5), foram homogeneizados com solução tampão de fosfato com inibidor de protease, em uma proporção de 2 $\mathrm{mL}$ da solução para cada $0,5 \mathrm{~g}$ de tecido, usando-se um homogeneizador mecânico. Homogenados hepáticos foram aliquotados em 3 microtubos de $2 \mathrm{~mL}$, destinados à quantificação da atividade EROD e determinação de proteínas totais, segundo metodologia de Bradford (1976), com adaptações para microplaca (Parente et al., 2004). 0 material reservado para EROD foi subseqüentemente centrifugado a $9000 \mathrm{~g}$ por $30 \mathrm{~min}$ à $4^{\circ} \mathrm{C}$, para obtenção da fração citosólica (S9) e armazenados em freezer -80 C para posterior quantificação da atividade enzimática.

\section{Análise enzimática}

A atividade enzimática da EtoxiresorufinaO-deetilase (EROD), foi determinada na fração hepática S9 através de ensaio descrito por Burker et al. (1985), modificado posteriormente por Pohl \& Fouts (1980) e Klotz et al, (1984), com adaptações para utilização do KIT CY P1A1 EROD ACTIVITY (IKZUS, Itália). Nesta reação, o substrato (etoxiresorufina) é hidrolizado à formação do produto fluorescente e estável (resorufina). A cinética enzimática pode ser seguida de 10 a 20 minutos com o uso de fluorímetro. Concentrações do substrato otimizado exógeno $\beta$-NADPH, juntamente com o uso de um tampão específico contendo inibidores de Diaforase e outras enzimas consumidoras de NADPH, permitem um bom desempenho da atividade da CYP1A1 EROD mesmo com baixas quantidades de homogenizado cru ou sobrenadante, obtido por centrifugação a $9000 \mathrm{~g}$ (fração pos-mitocondrial). Este procedimento é bastante rápido como também confiável e de fácil reprodutibilidade. A quantidade de resorufina formada foi mensurada, em triplicata a $30^{\circ} \mathrm{C}$ (I mber et al., 1995).

As dosagens foram realizadas em cubetas de quartzo, utilizando o espectrofluorímetro (Spectrofluorcephotometer-Shimadzu RF-5000), com excitação de $550 \mathrm{~nm}$, emissão de $582 \mathrm{~nm}$ e abertura da fenda $5 \mathrm{~nm}$, no laboratório de Toxicologia Ambiental da Escola Nacional de Saúde Pública - FIOCRUZ/RJ. A reação foi iniciada pela transferência $1,850 \mathrm{~mL}$ da solução $\mathrm{C}$ (tampão de reação) e $3 \mu \mathrm{L}$ de etoxiresorufina (Solução E) para a cubeta de quartzo e após 3 min pela adição de $50 \mu \mathrm{L}$ (ou 100 $\mu \mathrm{L}$ a depender da quantidade de proteínas totais obtidas) na fração S9. Após 2 min, adicionou-se 10 $\mu \mathrm{L}$ de $\beta$-NADPH, e a florescência (RFU - relative fluorescence unit) foi medida por um período total de 1,5 min, gerando um gráfico linear, através do qual foi obtido o $\triangle R F U$ (variação de intensidade de fluorescência). A quantidade de resorufina formada foi calculada através da equação da reta obtida na curva padrão de resorufina. A atividade da EROD foi calculada pela divisão da quantidade de resorufina formada (pmols) pela quantidade de proteínas totais presentes na reação (pmols/ mg de ptn), e pelo tempo de reação (pmols/mg proteínas/min) e, expressa em picomoles por minuto e por miligramas de proteínas da fração 59 .

\section{Exposição de compostos aromáticos}

O Ascarel, tecnicamente chamado de Alocloro 124, é um óleo resultante da mistura de hidrocarbonetos, derivados de petróleo, utilizado como isolante em equipamentos elétricos, sobretudo transformadores. Seu uso foi proibido, no Brasil em 1981, por apresentar risco ambiental avaliado com base em sua periculosidade em função da exposição (USEPA, 1986). A periculosidade está associada às potencialidades tóxicas intrínsecas da substância.

Por ser um composto formado por uma mistura de indutores de CYP1A1, ascarel foi utilizado no teste de controle positivo, empregando diferentes tratamentos com quantificação da indução de Atividade EROD, obedecendo à mesma metodologia. Nos tratamentos foram empregados: (a) uma concentração de 1:5 ( $1 \mathrm{~L}$ da fração solúvel de ascarel $+4 \mathrm{~L}$ de água de diluição) e (b) um controle com $5 \mathrm{~L}$ de água de diluição por réplica ( $\mathrm{C} 1$ a $\mathrm{C5}$ ); outro tratamento (c) foi por injeção intraperitonial com $25 \mu \mathrm{g} / \mathrm{L}$ e $100 \mu \mathrm{g} / \mathrm{L}$ de ascarel. Os indivíduos expostos a este último tratamento morreram antes de $24 \mathrm{~h}$ e seus fígados não foram utilizados na análise.

Neste trabalho, foram analisados os aromáticos: benzeno, tolueno, etil-benzeno, xilenos e C9's aromáticos na matriz água e sedimento. As análises foram realizadas no Laboratório de Cromatrografia e de Espectrometria do SENAI-CETIND, no município de Lauro de Freitas, BA, utilizando a técnica de cromatografia gasosa, para análise de poluentes prioritários voláteis [ MCRO 018 (EPA-8260)]. Foram realizadas também análises químicas de aromáticos [ MCRO 018 (EPA-8260)] (Benzeno, Tolueno, Etil-benzeno, $\mathrm{p}+\mathrm{m}$ to xilenos, C9's Aromáticos, Fenol, Naftaleno, Fenantreno e Antaceno) e metais [ MESP 110 (ASTM D5258/ 02)] , (Mercúrio, Cobre, Chumbo, Zinco, Níquel, Cromo, Ferro, Manganês, 
Alumínio, Cádmio e Arsênio), com o intuito de se conhecer a composição das amostras na água e no sedimento do açude.

A quantificação de aromáticos em sedimento foi realizada, tendo as amostras sido levadas em recipientes apropriados para a quantificação. Entretanto, só foi possível realizar essas amostragens no período chuvoso. As análises foram realizadas por cromatografia gasosa

\section{Tratamento estatístico}

Os dados foram analisados usando-se o teste t de Student, a fim de comparar médias; O ne-way Analysis of Variance (ANOVA) e Tukey-Kramer Multiple Comparisons Test, para comparar as variâncias das médias e comparação de médias múltiplas (GRAPHPAD INSTAT) entre os grupos amostrais e 0 controle. Diferenças significativas foram determinadas adotando um nível de probabilidade de 0,05. Cálculos estatísticos foram realizados utilizando os programas MINITAB, EXCEL e ORIGIN 1.6.

Para enriquecimento e exploração dos dados, foram realizadas Análises de Componentes Principais -PCA, com o intuito de verificar as variáveis mais importantes dentre os resultados. Análises de correlação entre os parâmetros físico-químicos e quantificação da atividade EROD para cada ponto foram realizadas, com o intuito de investigar as pos síveis causas do aumento ou decréscimo da atividade EROD.

\section{RESULTADOS}

\section{Resultados da Quantificação da Atividade ERO D}

0 resultado do teste de controle positivo utilizando Ascarel demonstrou que a exposição (fração solúvel 1:5 v/ v) ao poluente propiciou uma resposta cinco vezes maior que o controle negativo realizado, indicando uma atuação enzimática mais significativa do que com tratamento com injeção intraperitonial, cuja resposta da atividade apresentou aumento de duas vezes, quando comparada aos controles.

Os resultados dos testes obtidos com água superficial (Figura 2) caracterizam o ambiente como poluído por indutores de CY P1A1, evidenciado pelas maiores concentrações de atividade EROD, em alguns pontos de amostragem, quando comparadas ao controle. Através da comparação das médias nos dois períodos amostrais observa-se que, no período seco, a biodisponibilidade de HPA nos pontos P1, P2 e P3 no Açude de Retenção do Complexo Básico diferiram do controle, enquanto que no período chuvoso apenas o P2 diferiu do controle.

Os resultados dos testes obtidos com sedimento (Figura 3) mostraram uma maior atividade enzimática EROD, quando comparados ao controle e também quando comparados aos resultados dos testes com água superficial, confirmando a evidência de um ambiente sedimentar poluído por indutores de CY P1A1. Com base em comparação de médias múltiplas, os pontos P2 e P3 diferiram significativamente do controle, respectivamente nos períodos seco e chuvoso. Valores relativamente altos de HPAs, como benzeno, foram encontrados nas bacias de contenção, principalmente no P5 (Bacia do Cobre), onde entretanto a resposta EROD atingiu valores próximo ao controle negativo.
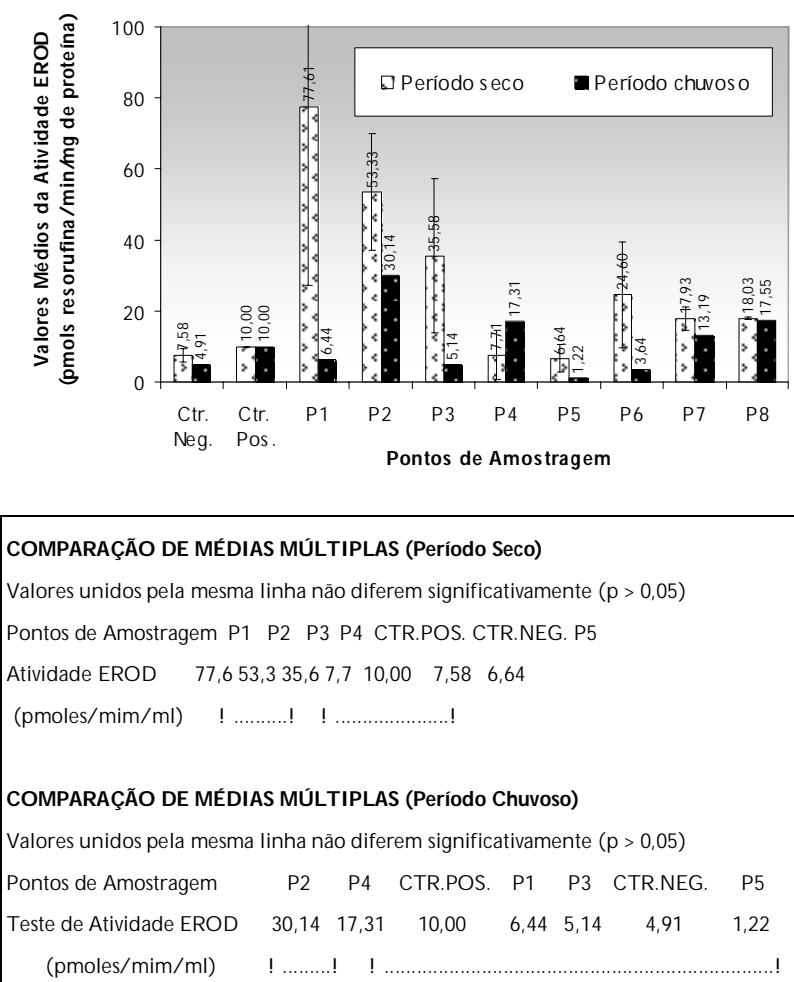

Figura 2 - Valores médios da indução da atividade ERO D (pmoles resorufina/ mg proteína/ min) em células hepáticas (fração S9) de tilápias (0. niloticus) expostas à água superficial.

Considerando os altos valores de metais pesados no sedimento e valores também relativamente altos de benzeno na água, detectados por análises químicas, supõe-se que a presença dos metais possa ter inibido a atividade EROD, visto que, os valores de metais obtidos através de análises químicas, foram altos em relação ao limite permissível pelas 
Resoluções CONAMA no 357/ 2005 e no 344/ 2004. Entretanto, pontos que tiveram valores de atividade EROD significativamente altos, quando comparados ao controle, também apresentaram valores altos de metais, não se podendo confirmar assim, se o nível de metal, influenciou diretamente na inibição da atividade EROD.

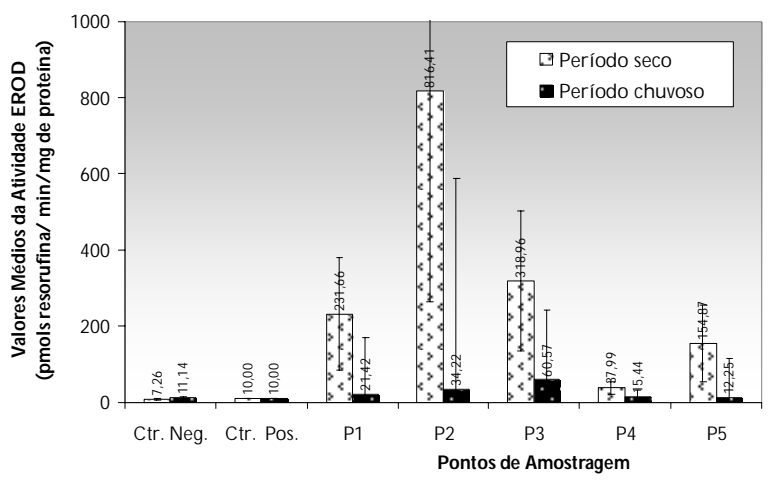

COMPARAÇÃO DE MÉDIAS MÚLTIPLAS (Período Seco)

Valores unidos pela mesma linha não diferem significativamente $(p>0,05)$ $\begin{array}{lllllll}\text { Pontos de Amostragem } & \text { P2 } & \text { P3 } & \text { P1 } & \text { P5 } & \text { P4 } & \text { CTR.POS. CTR.NEG. }\end{array}$

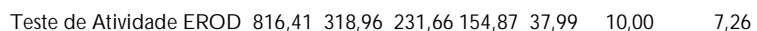

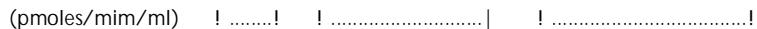

COMPARAÇÃO DE MÉDIAS MÚLTIPLAS (Período Chuvoso)

Valores unidos pela mesma linha não diferem significativamente $(p>0,05)$

$\begin{array}{lllllll}\text { Pontos de Amostragem } & \text { P3 } & \text { P2 } & \text { P1 } & \text { P4 } & \text { P5 } & \text { CTR.NEG. CTR.POS }\end{array}$

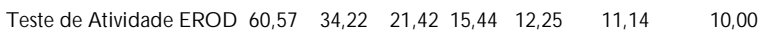

(pmoles/ mim/ ml) ! ......! ! ..........................................................

Figura 3 - Valores médios da indução da atividade ERO D (pmoles resorufina/ mg proteína/ min) em células hepáticas (fração S9) de tilápias (0. niloticus) expostas ao sedimento.

Os pontos que apresentaram maiores concentrações de poluentes indutores de CY P1A foram as bordas da Bacia do Complexo (P1 e P2 -borda oeste e leste do açude, respectivamente). Os valores de atividade EROD no período chuvoso, foram mais baixos do que os relacionados ao período seco com exceção do P4 (interior do Açude - próximo ao ponto de chegada do canal da Rua Hidrogênio) (Matias et al., 2006; Rodrigues et al., 2006a; Rodrigues et al., 2006b; Lacerda et al., 2006a; Lacerda et al., 2006b).

\section{Resultados da análise dos Parâmetros Ambientais}

As análises físico-químicas realizadas durante os experimentos indicaram pouca variação, e os valores obtidos se adequaram aos limites estabelecidos pela Resolução CONAMA no $357 / 05$, relativos à qualidade da água no corpo receptor.

T abela 01 - Valores Médios dos metais analisados no período seco (linha superior) e período chuvoso (linha inferior) nas amostras de água superficial.

\begin{tabular}{|c|c|c|c|c|c|c|}
\hline Parâmetro & Limite* & P1 & P2 & P3 & P4 & P5 \\
\hline \multirow{2}{*}{$\begin{array}{l}\text { Mercúrio } \\
(\mu g / L)\end{array}$} & \multirow[t]{2}{*}{$\varangle, 0002$} & 0,980 & 0,819 & 0,390 & 0,493 & 0,130 \\
\hline & & 0,523 & 0,760 & 0,630 & 0,257 & 0,033 \\
\hline \multirow{2}{*}{$\begin{array}{l}\text { Cobre } \\
\text { (mg/L) }\end{array}$} & \multirow[t]{2}{*}{$\varangle, 009$} & 0,198 & 0,042 & 0,062 & 0,148 & 0,188 \\
\hline & & 0,040 & 0,046 & 0,049 & 0,024 & 0,169 \\
\hline \multirow{2}{*}{$\begin{array}{l}\text { Chumbo } \\
\text { (mg/L) }\end{array}$} & \multirow[t]{2}{*}{$\varangle, 01$} & 0,074 & 0,038 & 0,028 & 0,041 & 0,032 \\
\hline & & 0,033 & 0,034 & 0,024 & 0,026 & 0,026 \\
\hline \multirow{2}{*}{$\begin{array}{l}\text { Zinco } \\
\text { (mg/L) }\end{array}$} & \multirow[t]{2}{*}{$\varangle, 18$} & 0,277 & 0,065 & 0,068 & 0,197 & 0,058 \\
\hline & & 0,118 & 0,069 & 0,052 & 0,075 & 0,059 \\
\hline \multirow{2}{*}{$\begin{array}{l}\text { Níquel } \\
\text { (mg/L) }\end{array}$} & \multirow[t]{2}{*}{$\varangle, 025$} & 0,068 & 0,051 & 0,053 & 0,049 & 0,079 \\
\hline & & 0,030 & 0,035 & 0,039 & 0,032 & 0,034 \\
\hline \multirow{2}{*}{$\begin{array}{l}\text { Cromo } \\
(\mathrm{mg} / \mathrm{L})\end{array}$} & \multirow[t]{2}{*}{$\varangle, 05$} & 0,036 & 0,023 & 0,017 & 0,025 & 0,010 \\
\hline & & 0,010 & 0,010 & 0,010 & 0,011 & 0,010 \\
\hline \multirow{2}{*}{$\begin{array}{l}\text { Ferro } \\
\text { (mg/L) }\end{array}$} & \multirow[t]{2}{*}{$\varangle 0,3$} & 1,761 & 0,508 & 0,803 & 1,532 & 1,069 \\
\hline & & 1,418 & 0,689 & 0,446 & 0,776 & 0,365 \\
\hline \multirow{2}{*}{$\begin{array}{l}\text { Manganês } \\
\text { (mg/ L) }\end{array}$} & \multirow[t]{2}{*}{$\varangle, 1$} & 0,361 & 0,146 & 0,188 & 0,342 & 0,049 \\
\hline & & 0,101 & 0,055 & 0,047 & 0,063 & 0,030 \\
\hline \multirow{2}{*}{$\begin{array}{l}\text { Alumínio } \\
\text { (mg/L) }\end{array}$} & \multirow[t]{2}{*}{$\varangle 0,1$} & 4,731 & 1,306 & 1,494 & 2,740 & 0,886 \\
\hline & & 6,083 & 2,478 & 1,286 & 2,684 & 6,792 \\
\hline \multirow{2}{*}{$\begin{array}{l}\text { Cádmio } \\
(\mathrm{mg} / \mathrm{L})\end{array}$} & \multirow[t]{2}{*}{$\varangle, 001$} & - & - & - & - & \\
\hline & & 0,009 & 0,009 & 0,009 & 0,009 & 0,009 \\
\hline \multirow{2}{*}{$\begin{array}{l}\text { Arsênio } \\
\text { (mg/L) }\end{array}$} & \multirow[t]{2}{*}{$\varangle 0,01$} & - & - & - & - & - \\
\hline & & 11,33 & 19,33 & 23,33 & 5,673 & 36,33 \\
\hline
\end{tabular}

* Limite Baseado na Resolução CONAMA no . 357/ 2005

N as amostras de água superficial e sedimento verificou-se a presença de metais traços essenciais e não essenciais como: Mercúrio, Zinco, Chumbo, Cromo, Ferro, Manganês e Alumínio (Tabelas 01 e 02). Vale ressaltar que a maioria dos metais analisados apresentou valores muito acima dos limites estabelecidos pela resolução CONAMA 357/ 05.

Os resultados das análises químicas revelaram que benzeno esteve presente em pelo menos um período, com volumes muito acima dos limites permissíveis (ver Figura 3), principalmente em pontos do interior do Açude (P2 e P3), que também apresentaram uma alta indução de atividade EROD (Figuras 1 e 2). As análises para etil-benzeno (Figura 4) e $p+m$ to Xilenos (Figura 5) demonstram que a área não sofre influência deste tipo de químicos de forma significativa. Os resultados obtidos no perío- 
do seco para tolueno revelam que existem pontos com valores aumentados acima do limite (Figura 6). Entretanto, quando comparados à atividade EROD, não há indicativo que a indução seja causada somente por esse tipo de contaminante.

Tabela 02 - Valores Médios dos metais analisados no período seco (linha superior) e período chuvoso (linha inferior) nas amostras de sedimento.

\begin{tabular}{|c|c|c|c|c|c|c|}
\hline Parâmetro & Limite* & P1 & P2 & P3 & P4 & P5 \\
\hline \multirow[t]{2}{*}{ Cobre $(\mu \mathrm{g} / \mathrm{Kg})$} & \multirow[t]{2}{*}{357,00} & 1135,0 & 2399,0 & 4181,3 & 1525,7 & 26394 \\
\hline & & 949,67 & 1810,0 & 2385,8 & 945,33 & 6808,1 \\
\hline \multirow{2}{*}{$\begin{array}{l}\text { Cromo } \\
(\mu \mathrm{g} / \mathrm{Kg})\end{array}$} & \multirow[t]{2}{*}{373,00} & 190,33 & 206,33 & 148,67 & 148,33 & 169,67 \\
\hline & & 114,33 & 98,40 & 104,77 & 71,33 & 25,43 \\
\hline \multirow{2}{*}{$\begin{array}{l}\text { Cádmio } \\
(\mu \mathrm{g} / \mathrm{Kg})\end{array}$} & \multirow[t]{2}{*}{60,00} & 6,07 & 10,67 & 22,67 & 11,03 & 56,00 \\
\hline & & 9,87 & 18,20 & 30,90 & 9,50 & 7,50 \\
\hline \multirow[t]{2}{*}{ Níquel $(\mu \mathrm{g} / \mathrm{Kg})$} & \multirow[t]{2}{*}{180,00} & 431,67 & 449,33 & 441,67 & 403,00 & 1229,7 \\
\hline & & 160,33 & 203,33 & 347,00 & 86,43 & 253,73 \\
\hline \multirow{2}{*}{$\begin{array}{l}\text { Chumbo } \\
(\mu \mathrm{g} / \mathrm{Kg})\end{array}$} & \multirow[t]{2}{*}{350,00} & 182,67 & 185,67 & 229,00 & 210,00 & 617,67 \\
\hline & & 186,00 & 186,33 & 217,33 & 15,30 & 149,20 \\
\hline \multirow[t]{2}{*}{ Zinco $(\mu \mathrm{g} / \mathrm{Kg})$} & \multirow[t]{2}{*}{1230,00} & 1151,0 & 2123,0 & 3271,7 & 1365,7 & 2132,3 \\
\hline & & 1054,3 & 2120,0 & 3946,7 & 797,33 & 474,50 \\
\hline
\end{tabular}

* Limite Baseado na Resolução CONAMA no . 357/ 2005

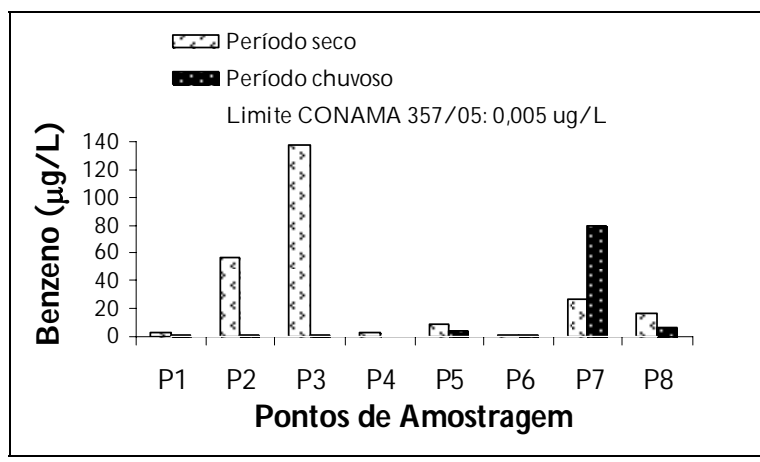

Figura 3 -Média dos valores de Benzeno $(\mu \mathrm{g} / \mathrm{L})$ anal isados na água superficial.

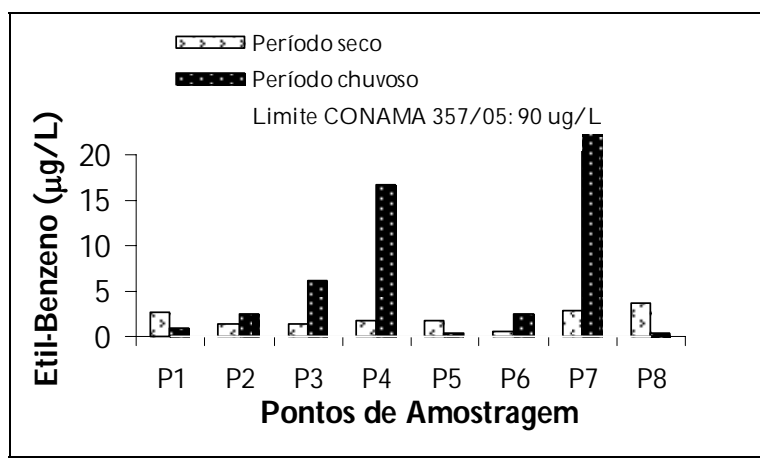

Figura 4 -M édia dos valores de Etil-benzeno ( $\mu \mathrm{g} / \mathrm{L}$ ) analisad os na água superficial.

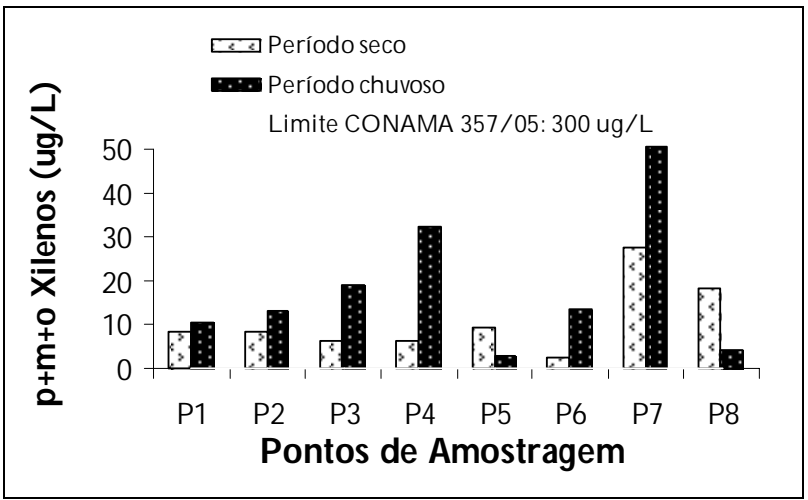

Figura 5-Média dos valores $p+m$ +o Xilenos $(\mu \mathrm{g} / \mathrm{L})$ analisados na água superficial.

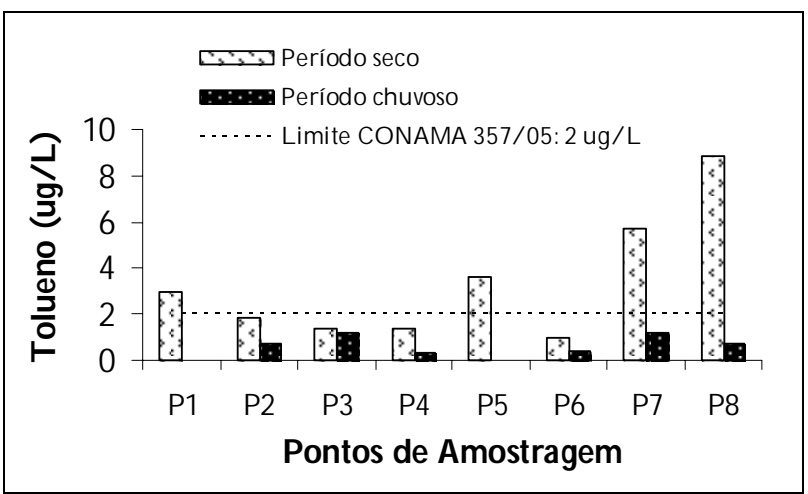

Figura 6 -M édia dos valores de T olueno $(\mu \mathrm{g} / \mathrm{L})$ analisados na água superficial.

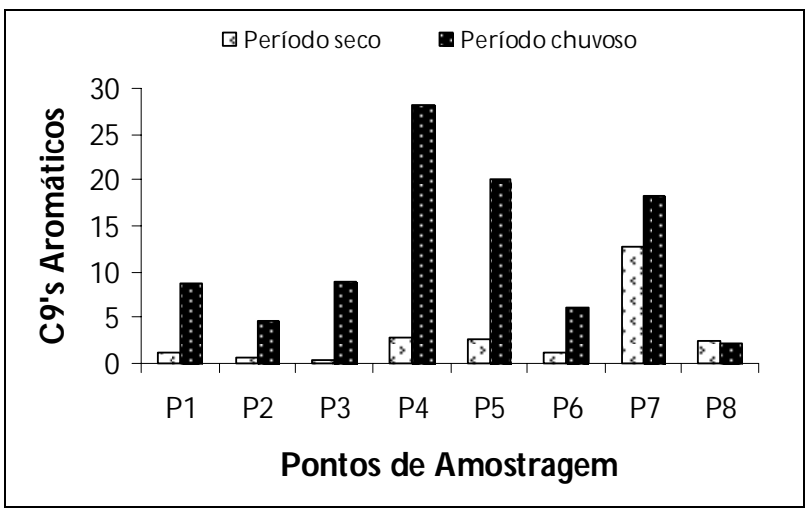

Figura 7 -Média dos valores de C9's Aromáticos $(\mu \mathrm{g} / \mathrm{L})$ analisados na água superficial.

Os resultados das análises de compostos aromáticos no sedimento por cromatografia gasosa são apresentados na Figura 8. Foi detectado a presença dos aromáticos na maioria dos pontos amostrados, com o tolueno se sobressaindo no P1. 


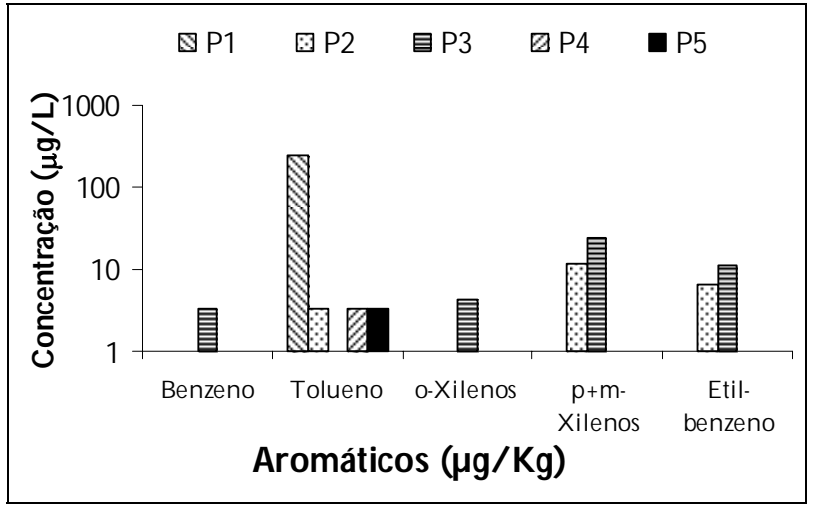

Figura 8 -M édia dos valores de Aromáticos $(\mu \mathrm{g} / \mathrm{Kg})$ analisados nos sedimentos. (O BS: Escala na base logarítimica)

Os C9's aromáticos apresentaram os maiores valores de registro nas análises realizadas no período chuvoso (Figura 7), diferentemente dos padrões encontrados na indução da atividade EROD. A resolução CONAMA no 357/05 não estabelece um valor de referência para estes contaminantes.

\section{Correlação entre EROD e parâmetros ambientais}

A correlação entre valores da atividade EROD e dados de análises químicas, mostrou toxicidade associada à presença metais na água, no período seco e chuvoso, como $\mathrm{Hg}, \mathrm{Hg}, \mathrm{Zn}, \mathrm{Cr}, \mathrm{Cu}, \mathrm{Ni}, \mathrm{Pb}$, $\mathrm{Fe}, \mathrm{Mn}$ e Al (ver Tabelas 3 e 4). Além da influência desses metais, houve também correlação positiva $\left(r^{2}>0,7 ; p \varangle 0,05\right)$ com os compostos aromáticos benzeno, tolueno, xilenos e etil-benzeno na água principalmente na chamada bacia do cobre.

No sedimento, houve correlação positiva entre a atividade $E R O D$ e a presença de metais $\mathrm{Cr}, \mathrm{Cd}$, $\mathrm{Cu}, \mathrm{Ni}, \mathrm{Pb}$ e $\mathrm{Zn}$, em todos os pontos do Açude do Complexo Básico e, na Bacia do Cobre (P5), apenas com o Cu. Em relação aos aromáticos, houve correlação positiva com Etilbenzeno, $\mathrm{m}+\mathrm{p}$ xilenos e o+xileno, principalmente na borda oeste e parte mais profunda do Açude.

A toxicidade desses pontos, para a água superficial, está associada principalmente à presença de benzeno, naftaleno, fenantreno e de ferro, na borda oeste (P1) e parte profunda do Açude (P3). No ponto $P 2$ houve uma forte associação da toxicidade com DQ $O\left(r^{2}=0,997 ; p \varangle 0,05\right)$. Para sedimento, de modo geral, a toxicidade esteve associada à presença de metais e os aromáticos etilbenzeno e xilenos.
Tabela 3 - Valores de correlação $\left(r^{2}>0,7 ; p \varangle 0,05\right)$ entre a atividade EROD das campanhas de período seco e resultados de análises químicas, em cada ponto amostral.

\begin{tabular}{|c|c|c|}
\hline Matriz & $\begin{array}{l}\text { Pon- } \\
\text { to }\end{array}$ & Correlação $\left(r^{2}>0,7 ; p<0,05\right)$ \\
\hline \multirow{5}{*}{$\begin{array}{l}\text { Água } \\
\text { super- } \\
\text { ficial }\end{array}$} & P1 & $*$ \\
\hline & P2 & $\begin{array}{l}\text { DQO }(0,997), \mathrm{Hg}(0,994), \mathrm{Zn}(0,730) \text {, } \\
\mathrm{Cr}(0,999)\end{array}$ \\
\hline & P3 & Benzeno $(0,869), \mathrm{Al}(0,821)$ \\
\hline & P4 & $\begin{array}{l}\mathrm{Hg}(0,999), \mathrm{Zn}(0,881), \mathrm{Ni}(0,756), \mathrm{Cr} \\
(0,941), \mathrm{Al}(0,800)\end{array}$ \\
\hline & P5 & $\begin{array}{l}\text { DQO }(0,800) \text {, Benzeno }(0,911), \mathrm{To}- \\
\text { lueno }(0,952), \text { Xilenos }(0,959), \mathrm{Cr} \\
(0,866), \mathrm{Fe}(0,872)\end{array}$ \\
\hline \multirow{5}{*}{$\begin{array}{l}\text { Sedim } \\
\text { ento }\end{array}$} & P1 & $\mathrm{Cd}(0,876), \mathrm{Zn}(0,907)$ \\
\hline & P2 & $\begin{array}{l}\mathrm{Cr}(0,861), \mathrm{Cu}(0,866), \mathrm{Ni}(0,773), \mathrm{Pb} \\
(0,911)\end{array}$ \\
\hline & P3 & $\begin{array}{l}\mathrm{Cr}(0,868), \mathrm{Cu}(0,829), \mathrm{Ni}(0,734), \mathrm{Pb} \\
(0,911)\end{array}$ \\
\hline & P4 & $\mathrm{Cd}(0,866), \mathrm{Zn}(0,998)$ \\
\hline & P5 & $\mathrm{Cu}(0,962)$ \\
\hline
\end{tabular}

(*) Não apresentou correlação significativa $\left(r^{2}>0,7\right)$.

Tabela 4 - Valores de correl ação $\left(r^{2}>0,7 ; p \varangle 0,05\right)$ entre a atividade ERO D das campanhas de período chuvoso e resultados de anál ises químicas, em cada ponto amostral.

\begin{tabular}{|c|c|c|}
\hline Matriz & $\begin{array}{l}\text { Pon- } \\
\text { to }\end{array}$ & Correlação $\left(r^{2}>0,7 ; p<0,05\right)$ \\
\hline \multirow{5}{*}{$\begin{array}{l}\text { Água } \\
\text { super- } \\
\text { ficial }\end{array}$} & $\mathrm{P} 1$ & $\mathrm{~Pb}(0,793), \mathrm{Cr}(0,976)$ \\
\hline & P2 & DQO (935), Cr $(0,719) \mathrm{Mn}(0,719)$ \\
\hline & P3 & $\begin{array}{l}\mathrm{Pb}(1,000), \mathrm{Zn}(1,000), \mathrm{Cr}(1,000) \text {, } \\
\mathrm{Mn}(0,756)\end{array}$ \\
\hline & P4 & $\begin{array}{l}\text { Benzeno }(0,967), \quad \mathrm{Hg}(0,812), \mathrm{Pb} \\
(0,967), \mathrm{Cr}(0,967), \mathrm{Zn}(0,924)\end{array}$ \\
\hline & P5 & $\begin{array}{l}\text { Benzeno }(0,944), \mathrm{Hg}(0,867), \mathrm{Cr} \\
(0,867)\end{array}$ \\
\hline \multirow[t]{5}{*}{$\begin{array}{l}\text { Sedim } \\
\text { ento }\end{array}$} & P1 & $\begin{array}{l}\mathrm{Cd}(0,992), \mathrm{Cu}(0,790), \mathrm{Ni}(0,740), \\
\mathrm{Pb}(0,854), \mathrm{Zn}(0,935\end{array}$ \\
\hline & $\mathrm{P} 2$ & Etilbenz $(0,720), m+p$ xileno $(0,970)$ \\
\hline & P3 & $\begin{array}{l}\text { Etilbenz }(0,977), m+p \text { xileno }(0,823) \text {, } \\
\text { o-xileno }(0,977)\end{array}$ \\
\hline & $\mathrm{P} 4$ & $\mathrm{Cu}(0,868)$ \\
\hline & P5 & $*$ \\
\hline
\end{tabular}

(*) Não apresentou correlação significativa $\left(r^{2}>0,7\right)$.

Os valores de correlação em negrito indicam os pontos onde houve toxicidade significativa em relação ao controle. 


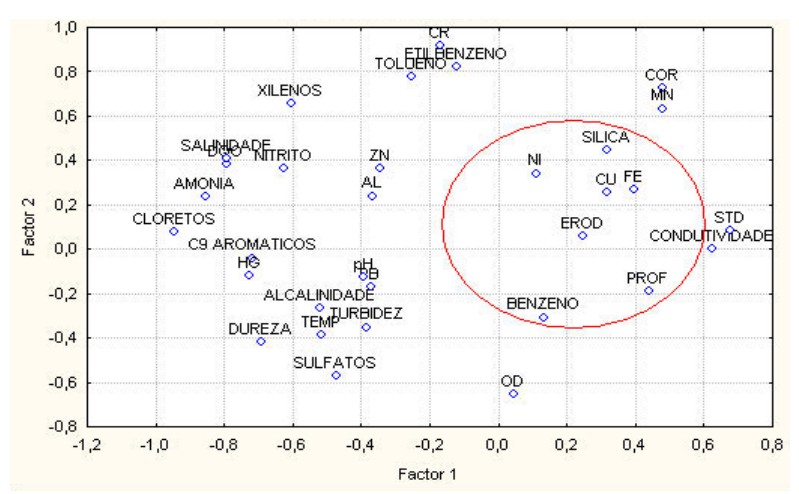

Figura 9 - Análise de Componentes Principais em O reochromis niloticus através dos testes relacionados à indução da atividade ER OD com os parâmetros ambientais analisados, durante o período seco.

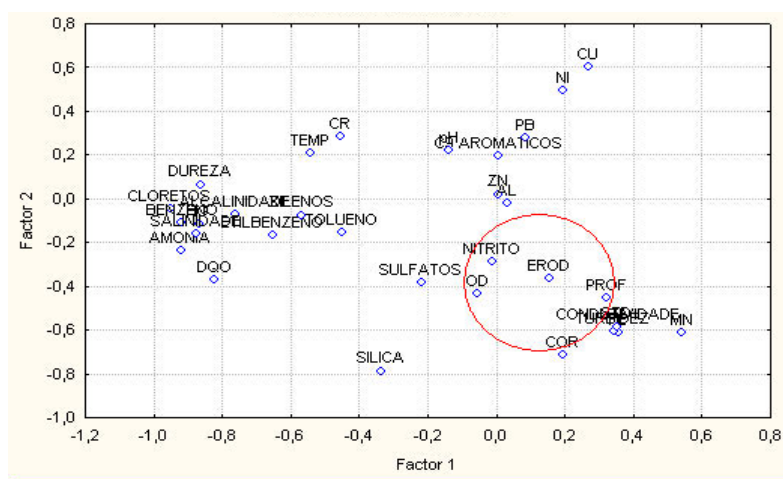

Figura 10 - Análise de Componentes Principais em 0 reochromis niloticus através dos testes relacionados à indução da atividade ER OD com os parâmetros ambientais analisados, durante o período chuvoso.

Os resultados dos testes obtidos com água superficial e sedimento indicam que ecossistema aquático analisado está contaminado por indutores de CY P1A1 (que incluem HPAs carcinogênicos), 0 que foi evidenciado analiticamente pelas mais altas concentrações de atividade EROD, em alguns pontos de amostragem, quando comparadas ao controle. As determinações da atividade de Citocromo P450 mostraram evidências de exposição a HPA's, principalmente nos pontos de coleta P1, P2 e P3 (respectivamente borda oeste, borda leste e centro do açude do Complexo Básico). Com base nos resultados de correlação, a toxicidade desses pontos, para a água superficial, está associada principalmente à presença de benzeno, naftaleno, fenantreno e de ferro, na borda oeste (P1) e parte profunda da Açude (P3); no ponto P2 houve uma forte associação da toxicidade com DQO ( $r 2=0,997 ; p \varangle 0,05$ ). Para sedimento, de modo geral, a toxicidade esteve associada à presença de metais e os aromáticos etilbenzeno e xilenos. Em relação à análise de PCA, a presença do benzeno e alguns metais, tais como $\mathrm{Ni}, \mathrm{Cu}$, Fe demonstra uma relação com a atividade EROD para efluente, além de alguns parâmetros ambientais tais como DQO e Nitrito que podem ser comprovados pela análise de correlação em alguns pontos de amostragem.

\section{DISCUSSÃO}

Estes resultados indicam a necessidade de incorporação de tecnologias que maximizem a retenção destes contaminantes na fonte nas diferentes etapas de produção em complexos industriais e na adoção e seleção de processos adequados de descontaminação da massa hídrica efluente, com isso, inclusive, facilitando o seu reaproveitamento nos processos. Para reuso, este deve ser precedido de uma análise em função dos objetivos de uso, para que se evitem riscos à saúde do ambiente. Todavia, o uso desta área para fins não industriais (como pesca e contato direto) não é recomendado devido à extrapolação dos limites dos parâmetros químicos e físicos baseados nas Resoluções CONAMA 357/ 2005 e $344 / 2004$, e do acentuado valor de atividade enzimática EROD em alguns pontos; esta resolução estabelece limites iniciais, mas não específicos para caracterizar um bom parâmetro definitivo, para a presença desses compostos no ecossistema.

Por fim, a metodologia empregada para detectar a biodisponibilidade de compostos aromáticos em corpos hídricos, mostrou-se viável (de ponto de vista metodológico e também técnico) e com boa confiabilidade, além de atuar proativamente num nível inicial de impactação, permitindo a tempo a execução de ações que previnam impactos ambientais em níveis superiores de organização da biota. Entretanto a técnica também apresenta algumas limitações, como a rápida leitura das amostras e sensibilidade dos reagentes.

A escolha do organismo teste, tilápia, foi bem direcionada, visto que o organismo corresponde bem à altas variações ambientais, além de ser bem resistente à exposição dos compostos, e ser um organismo da biota local.

Os pontos amostrais foram determinados por estudos prévios (relizados por empresas do Polo, comunicação pessoal por técnicos) e sua cobertura favoreceu a identificação da heterogeneidade 
do açude, inclusive em função dos canais de entrada dos efluentes e saída do mesmo.

Como ferramenta de monitoramento a atividade EROD provou ter uma ação relativamente rápida em peixes expostos à compostos tóxicos planares, tendo uma contribuição significativa na avaliação da qualidade da água de ecossistemas aquáticos. Assim, a EROD é frequentemente referência a um "sistema de aviso rápido" (Beiras, 2006), para predizer riscos ambientais por contaminantes.

\section{AGRADECIMENTOS}

À FINEP pelo financiamento à pesquisa do projeto ECOBRASKEM (TECLIM/UFBA). À FAPESB pela bolsa de mestrado. Ao Dr. Francisco Paumgartten pela recepção no Laboratório de Toxicologia Ambiental (FIOCRUZ/RJ) onde as análises foram realizadas. Ao DNOCS, por meio da Sra. Louirânia S. de Souza, pela doação dos organismos-teste.

\section{REFERÊNCIAS}

ADAMS, S. M.; JAWORSKA, J.S.; HAM, K.D. (1996) Influence of Ecological factors on the relationship between MFO induction and fish growth: BGridging the Gap using Neural Networks. Marine Environmetal Research, Vol.42, n1-4: 197-201.

AXARLI, I.; PRIGIPAKI, A.; NIKOLAOS, E. L. (2005). Engineering the substrate specificity of cytocrome P450 CYP102A2 by directed evolution: production of an efficient enzyme for bioconversion of line chemicals. Biomolecular Engineering, 22:81-88.

BAINY, A.C. (2001). Expressão do complexo citocromo P4501A e das metalotioneínas na avaliação da contaminação aquática. In: Efeitos de Poluentes em Organismos Marinhos.269-285p.

BAINY, A.C.D.; SAITO, E.; CARVALHO, P.S.M.; JUNQUEIRA, V.B.C. (2001). Oxidative stress in gill, erythocytes, liver and kidney of Nile tilapia (Oreochromis niloticus) from a polluted site. Aquatic. Toxicol. 34, 151-162.

BEIRAS, R. Respostas celulares e moleculares: Biomarcadores. Biotransformacion e eliminacion de sustancias tóxicas: alteracións lisosómicas. Methods in Aquatic Toxicology. 2006.

BISTOLAS, N.; WOLLENBERG, U.; JUNG, C.; SCELLER, W. (2005). Cytochrome P450 biosensors - a review. Biosensors and Bioeletronics. 20: 2408-2423.
BRADFORD. (1976): A rapid and sensitive method for the quantification of microgram quantities of protein utilizing yhe principle of protein dye binding. An. Biochem. 72, 248-254.

BURKER, D.M.; THOMPSON, S.; ELCOMBE, C. R.; HALPERT, J.; HAAPARANTA, T.; MAGER, R.T. (1985) Ethoxy-, pentoxy- and benzyloxyoxazones and homologues: a series of substrates to distinguish between different induced cytochrome P-450. Biochem Pharmacol 34: 3337-3345.

BURGEOT, T.; BOCQUENE, G.; PORTE, C.; DIMEET, J.; SANTELLA, R.M.; GARCIA, P.L.M.; PFHOLLESZKOWICZ, A.; RAOUX, C.; GALGANI, F. (1996). Bioindicators of pollutant exposure in the northwestern Mediterranean Sea. Marine Ecology Progress Series. v131, 235-248p.

CETESB - COMPANHIA DE TECNOLOGIA DE SANEAMENTO AMBIENTAL. Desenvolvimento de métodos para o estabelecimento de critérios ecotoxicológicos: relatório final. São Paulo, 1986. 174 pp.

CETESB - COMPANHIA DE TECNOLOGIA DE SANEAMENTO AMBIENTAL (1990a). Procedimento para utilização de testes de toxicidade no controle de efluentes líquidos. São Paulo. Setembro.

CETESB - COMPANHIA DE TECNOLOGIA DE SANEAMENTO AMBIENTAL (1990b) Implementação de testes de toxicidade no controle de efluentes líquidos. São Paulo. Outubro.

CONAMA - CONSELHO NACIONAL EM MEIO AMBIENTE. Resolução № 344, de 25 de março de 2004. Estabelece as diretrizes gerais e os procedimentos mínimos para a avaliação do material a ser dragado em águas juridicionais brasileiras, e dá outras providências. São Paulo 11p. 2004.

CONAMA - CONSELHO NACIONAL EM MEIO AMBIENTE. Resolução № 357, de 17 de março de 2005. Dispõe sobre a classificação dos corpos de água e diretrizes ambientais para o seu enquadramento, bem como estabelece as condições e padrões de lançamento de efluentes, e dá outras providências. São Paulo 24 p. 2005.

EHLERS-MARCUSSEN, M.G.E.; BARRA, R. (1997). Enzimas Citocromo P450. Universidad de Concepcion. Centro EULA-Chile.

HUEVEL, M.R.V.D.; MUNKITTRICK, K.R.; STEGEMAN, J.J.; DIXON, D.G. (1995). Second-round interlaboratory comparison of hepatic ethoxyresorufin-O-deethylase activity in white sucker (Catostomus commmersoni) exposed to Bleached-kraft pulp mill effluent. Environmental Toxicology and Chemistry, V.14, n.9: 1513-1520.

IMBER, B.E.; SPENCE, B.; CHAN, Z.; AGGELEN, G.V. (1995) Temporal variation in Hepatic Mixed-Function Oxidase (MFO) induction in rainbow trout exposed to in- 
dustrial effluent. Marine Pollution Bulletin, Vol. 30, n08, pp 558-562.

KLOTZ, A.V.; STEGEMAN, J.J.; WALSH, C. (1984) An alternative 7-ethoryresorufin-O-deetylase activity assay: a continuous visible spectrophotometric method for measurement of cytochrome P-450 monooxygenase activity. Anal. Biochemic. Vol 107: 150-155.

LACERDA, V.C.O.; PEREIRA, S.A.; NASCIMENTO, I.A.; BARROS, D.A.; LEITE, M. B. N. L.; CRUZ, A.C.S.; RODRIGUES, I.L.P.; MATIAS, G.R.A.; SANTOS, D.S.; NASCIMENTO, T. B. Avaliação da qualidade de água da bacia de retenção de efluentes nãoorgânicos do Polo Petroquímico de Camaçari-BA: teste ecotoxicológico utilizando a microalga Pseudokirchneriella subcapitata. In: IX Congresso Brasileiro de Ecotoxicologia, São Pedro.: Editora e Gráfica Vida e Consciência, v. 1. p. 133-133, 2006a.

LACERDA, V.C.O.; NASCIMENTO, I.A.; PEREIRA, S.A.; LEITE, M.B.N.L.; CRUZ, A.C.S.; BARROS, D. A.; RODRIGUES, I.L.P.; MATIAS, G.R.A.; SANTOS, D.S. Importância de parâmetros físico-químicos para avaliação da qualidade da água das bacias receptoras de efluentes das empresas do Pólo Petroquímico de Camaçari-BA. IX Congresso Brasileiro de Ecotoxicologia, São Pedro: Editora e Gráfica Vida e Consciência, v. 1. p. 188-188. 2006b

LAM, P.K.S.; WU, R.S.S. (1999). Use of Biomarkers in Environmental Monitoring. Scientif and Technical Advisory Panel.

MATIAS, G.R.A.; NASCIMENTO, I.A.; PEREIRA, S.A.; LEITE, M.B.N.L.; CRUZ, A.C.S.; BARROS, D.A.; RODRIGUES, I.L.P.; LACERDA, V.C.O.; SANTOS, D.S. Utilização de Citocromo P450 como biomarcadores de contaminação por hidrocarbonetos poliaromáticos (HPAs) em Corpos de Água. In: IX Congresso Brasileiro de Ecotoxicologia, São Paulo : Editora e Gráfica Vida e Consciência, v. 1. p. 147-147. 2006.

MEDIONDO, E.M.; Martins, E. S. R. P.; BERTONI, J. C. Gestão de incertezas hidrológicas no auxílio às políticas hídricas para o manejo integrado de bacias. GESTÃO DAS INCERTEZAS HIDROLÓGICAS NO AUXÍLIO ÀS POLIITICAS HÍDRICAS PARA O MANEJO INTEGRADO DE BACIAS. XIX Congreso Nacional del Água, Villa Carlos Paz, Córdoba, Argentina - Anales - 13 a 16 de Agosto de 2002

NASCIMENTO, I.A. (2000). Novos paradigmas da ecotoxicologia: resultados de testes ecotoxicológicos requerem validação em campo. Rev. Brás. de Toxicologia. 13(2), 23-28.

NASCIMENTO, I.A. (2002). Técnicas de coleta, preservação e preparo de amostras líquidas e de sedimentos para testes de toxicidade. In: Métodos em Ecotoxicologia Marinha: aplicações no Brasil. Cap. II. São Paulo. Editora Artes Gráficas e Indústria Ltda. 262p.
NEBERT, M.; THOMTON, R.D.; STUEBING, E. W.; HARLOW, P. (2000). Clinical importance of the cytochromes P450. J. Biol. Chem, 266 Lancet 360:1155-1162.

PAIVA, J.B.D.; PAIVA, E.M.(2002) Hidrologia aplicada à gestão de pequenas Bacias Hidrográficas. Universidade Federal da Santa Maria. ABRH. 491pp.

PARENTE, T.E.M.; DE-OLIVEIRA, A.C.A.X.; SILVA, I.B.; ARAUJO, G.A.; PAUMGARTTEN, F.J.R.(2004) Induced alkoxyresorufin-O-dealkylases in tilapias (Oreochromis niloticus) from Guandu river, RJ, Brazil. Chemosphere 54: 1613-1618.

PEDROZA, M.F.M.; BARBOSA, E.M.; CORSEUIL, H.X.; SCHNEIDER, M.R.; LINHARES, M.M. (2002). Ecotoxicologia e avaliação de risco do petróleo. Série Cadernos de Referência Ambiental. Centro de Recursos Ambientais. V.12. 228pp.

POHL, R.J.; FOUTS, J.R.(1980) A rapid method for assaying the metabolism of 7-ethoxyresorufin by microsomal subcellular fraction. Anal. Biochem. Vol. 107:150155.

REES, C.B.; WU, H.; LI, W. (2005) Cloning of CYP1A in Atlantic salmon (Salmo salar). Aquaculture 246: 11-23.

RODRIGUES, I.L.P.; NASCIMENTO, I.A.; PEREIRA, S.A.; LEITE, M.B.N.L.; CRUZ, A.C.S.; BARROS, D.A.; MATIAS, G.R.A.; LACERDA, V.C.O.; SANTOS, D.S. Utilização de Metalotioneínas como biomarcadores de contaminação por metais traços em bacia de retenção de efluentes petroquímicos utilizando Oreochromis niloticus como organismos teste. In: IX Congresso Brasileiro de Ecotoxicologia, São Pedro: Editora e Gráfica Vida e Consciência, v. 1. p. 147-147. 2006a.

RODRIGUES, I.L.P; NASCIMENTO, I.A.; PEREIRA, S.A.; CRUZ, A.C.S.; LEITE, M.B.N.L.; BARROS, D.A.; MATIAS, G.R.A.; LACERDA, V.C.O.; SANTOS, D.S. Uso de biomarcadores bioquímicos na avaliação da qualidade de efluentes e sedimento da bacia de retenção do Complexo Básico do Polo Petroquímicod de Camaçari-BA, utilizando Oreochromis niloticus como organismos teste. In: IX Congresso Brasileiro de Ecotoxicologia, São Pedro: Editora e Gráfica Vida e Consciência. v. 1. p. 149-149. 2006b.

SIROKA, Z.; KRIJT, J.; RANDAK, T.; SVOBODOVÁ, Z.; PESKOVA, G.; FUKSA, J.; HAJSLOVA, J.; JARKOVSKY, J.; JANSKA, M. (2005). Organic Pollutant Contamination of the River Elbe as Assessed by Biochemical Markers. ACTA Vet. BRNO, 2005, 74: 293-303.

SLEIDERINK, H.M.; OOSTING, J.; GOKSOYR,A.; BOON, J.P. (1995) Sensitivity of cytochrome P450 1A induction in dab (Limanda limanda) of different age and sex as a biomarker for on environmental contaminants in the southern North Sea. Arch. Environ. Contam. Toxicol., 1995, 28: 423-430.

USEPA. Quality Criteria for Water EPA 440/5-86-001. 1986. 
Ecotoxicological Assessment in Water Bodies - A

Case Study: Detention Pond of the Petrochemical Plant of Camaçari, Bahia

\section{ABSTRACT}

Aromatic compounds are very important in environmental monitoring due to their carcinogenic potential and their capability of modifying gene expression that re sults in protein formation. This induction can be determined by specific techniques for H PAs, PCBs and OrganicChlorinated Dioxins. The paper presents the findings of a research study aiming to evaluate the bioavailability of aromatic compounds in a pond that retains run-off from industrial areas of the Petrochemical Plant of Camaçari (Bahia state). The experiments were based on the biological response of "tilapias" (Oreochromis niloticus) exposed to water and sediment samples. A nalyses were based on en zymatic induction, by xen obiotic oxidation, a procedu re that has already proved successful as exposure biomarkers to HPAs and others industrial pollutants. This technique is associated with increased enzyme activity in liver cells, a first sign allowing the evaluation of the presence/ absen ce of aromatic compounds in the environment. Results showed that fish were exposed to protein CYP1A inductors, since they presented significant in crease in the en zymatic activity of Ethoxyresorufin-0-deethylase (EROD). Even though chemical analysis detected the presence of aromatic compounds at the site, tests with the biomarker su ggested moderate contamination, probably due to the weak bioavailability of the pollutants. This study provided further information and allowed testing a new approach that can be replicated for environmental preservation, especially for water bodies.

Key-words: contamination; pollution; aromatic compounds; biomarkers; prevention; environmental impacts. 